\title{
COMPARATIVE HYGIENIC EVALUATION OF ARC WELDING PROCESS AT CONSTANT AND PULSED ELECTRODE WIRE FEED
}

\author{
O.G. LEVCHENKO, S.Yu. MAKSIMOV, A.O. LUKIANENKO and I.V. LENDEL \\ E.O. Paton Electric Welding Institute, NASU \\ 11 Bozhenko Str., 03680, Kiev, Ukraine. E-mail: office@paton.kiev.ua
}

\begin{abstract}
The problem of improving the sanitary-hygienic characteristics in welding zone is solved by designing and equipping the welder workplace with a local exhaust, completing of welding heads and holders for mechanized welding with nozzles of special design which provide suction of welding fume or application of a protective mask with a system of forced purified air supply. All this additionally complicates and increases the cost of welding equipment. Therefore, the investigations are carried out aimed at study of influence of power parameters (voltage and current) of welding process on the volume of welding fumes evolution and their harmful components. The hygienic characteristics of arc welding process in shielding gases at a constant electrode wire feed using circuits of electrical parameters control of welding power sources of serial production as well as pulsed control of electric parameters of arc for electrode metal transfer are well studied and presented in the technical literature. The possibilities of influence of welding process with a pulsed electrode wire feed on hygienic characteristics were studied not enough. Therefore, in this paper the results of comparative hygienic evaluation of arc welding at pulsed and constant feed of electrode wire of different grades are presented. The advantages and possibilities of reducing evolution of harmful substances in the air of working area are shown applying welding with pulsed wire feed and selecting the appropriate parameters of its feeding mode. 14 Ref., 3 Figures.
\end{abstract}

Key words: arc welding, mechanized equipment, electrode wire, pulsed feed, hygienic characteristics, reduction of fumes evolution

One of the ways to improve the sanitary-hygienic characteristics of arc welding is the use of pulsed power sources, allowing reducing the excessive power of the arc, control of electrode metal transfer, reducing its spattering and, therefore, reducing the evolution of harmful substances contained in welding fumes (WF) to the air of the working area [1-3]. Recently for arc welding in shielding gases the equipment of a new type, i.e. automatic and semiautomatic machines with a pulsed electrode wire feed, become ever more widespread [4]. Thus, on the basis of computerized brushless direct current electric drive with fully controllable parameters of pulsed electrode wire movement (values of speeds in the pulse and reverse, time of pulses and pauses action, pulse frequency, value of duty cycle) it is possible to improve the quality of welded joints, to control the geometry of the weld, decrease the power and resource consumption during welding process and, probably, to reduce the evolution of harmful substances into the air of the working area. The latter remains a very urgent task in solving the problems of welder and environment protection from harmful inevitable evolutions of WF, especially when using alloyed electrode wires [5-7].

The aim of this work is to determine the possibilities of influencing the method of arc welding with a controllable pulsed electrode wire feed on hygienic characteristics of welding process and selection of modes providing decrease in evolution of harmful substances.

To find the ways of reducing the evolution of harmful substances contaminating the air of industrial environment during mechanized welding, the effect of pulsed electrode wire feed and welding mode on indicators of evolution of WF formed while performing the process in the mixture of shielding gases $\left(\mathrm{Ar}+18 \% \mathrm{CO}_{2}\right)$ using solid wires of grades $\mathrm{Sv}-08 \mathrm{G} 2 \mathrm{~S}, \mathrm{~Sv}$ 01Kh19N18G10AM4 (EP-690) of $1.2 \mathrm{~mm}$ diameter, and in $\mathrm{CO}_{2}$ with flux-cored wire Veltek-N320 of $1.6 \mathrm{~mm}$ diameter, containing chromium, nickel, manganese, fluorines and other components, was investigated. The dependencies of intensity of WF formation and their main toxic components on welding mode with electrode wire pulsed feed were investigated. Welding was applied with a pulsed electrode wire feed and (for comparison) with a continuous feed of solid wire at $160 \mathrm{~A}$ and $21-22 \mathrm{~V}$ mode and of flux-cored wire at $230 \mathrm{~A}$ and $26-27 \mathrm{~V}$. In the investigations 
the pulse frequency of electrode wire feed aquired $f=20,40,60 \mathrm{~Hz}$, and the relative pulse duration $s=2,3$ and 5 . The constant electrode wire feed was set by the frequency of $1 \mathrm{~Hz}$ at the pulse duration of 1 unit [8]. The shielding gases were selected according to the recommendations of electrode wire manufacturers, and welding modes were selected from the recommended ranges of current and voltage depending on the type of electrode wire and its diameter [9].

The determination of hygienic indicators of WF evolution was carried out in accordance with the standard [10]. The investigations of intensity of WF evolution were carried out using the method of «full capture». To determine the chemical composition of WF the methods of sanitary-chemical analysis were used [11].

Welding using wire Sv-08G2S in $\mathrm{Ar}+\mathrm{CO}_{2}$ mixture. The results of investigations (Figure 1, a) showed that in welding with a constant feed of electrode wire Sv-08G2S the maximum intensity of WF formation is observed. When applying all other modes of welding with a pulsed feed it is $1.2-2$ times decreased.

The investigation of dependencies of intensity of WF formation on the frequency and duration of pulses in welding using wire Sv-08G2S in the mixture of shielding gases $\mathrm{Ar}+\mathrm{CO}_{2}$ (see Figure $1, a$ ) determined that they have a complex form. Thus, in welding at $f=20 \mathrm{~Hz}$ the intensity of WF formation decreases with increase in pulse duration, and at $f=40 \mathrm{~Hz}$, on the contrary, it is increased, and at $f=60 \mathrm{~Hz}$ this dependence is ambiguous.

The complex view of the obtained dependencies can be explained as follows. It is known that in welding with constant electrode wire feed in shielding gas the level of WF evolution is determined not only by the arc power, but also

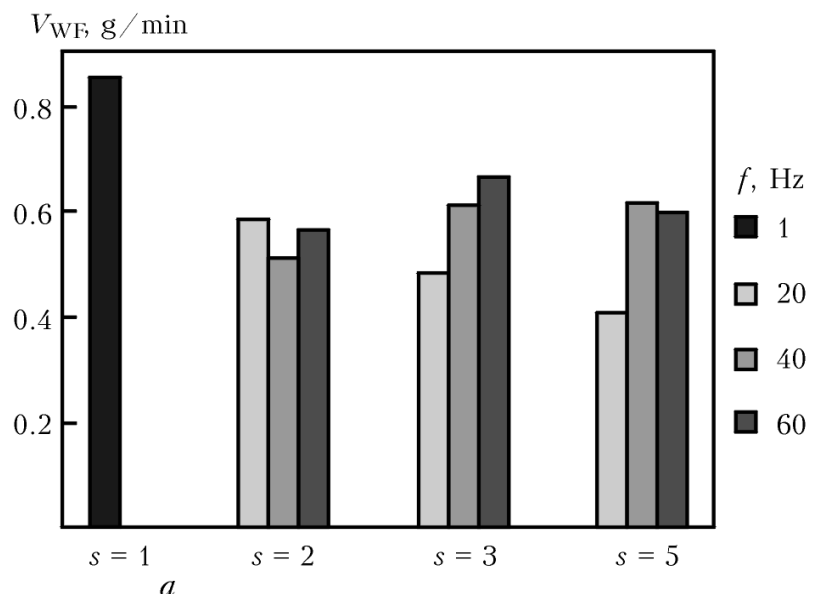

by the character of electrode metal transfer [12]. The dependence of intensity of WF formation on welding current bears an extreme character: at first, it is increased and, then, decreased and has a maximum corresponding to the greatest spattering of electrode metal and a minimum, characteristic for fine-drop transfer without short circuits with immersion of arc into the base metal [13]. In its turn, it is known [14] that in pulsed electrode wire feed depending on feed step the following three variants of electrode metal transfer are possible:

- feed step is equal or somewhat larger than the arc length, and the drop is dipped into the molten pool during movement of the electrode;

- feed step is somewhat smaller than the arc length and the electrode metal drop without its detachment comes into contact with weld pool after depay under the forces of inertia;

- feed step is smaller than the arc length and the drop detaches under the action of inertia forces and flies over the arc gap without a short circuit.

Therefore, the view of the diagram (see Figure 1, $a$ ) depends on the certain area of dependencies of intensity of WF formation on welding current and the available variant of electrode metal transfer considered at the moment.

As is known, welding using modulated pulsed current allows reducing the intensity of WF evolution (as compared to welding using continuous current) without reducing the labor efficeincy and melting coefficient $[1,3]$. The reduction of total arc power due to the pauses during application of pulsed current reduces the excess of energy occured in welding using continuous current and is spent for evaporation of fusible materials. The intensity of WF formation decreases with decrease in currents in the pulse, pause,

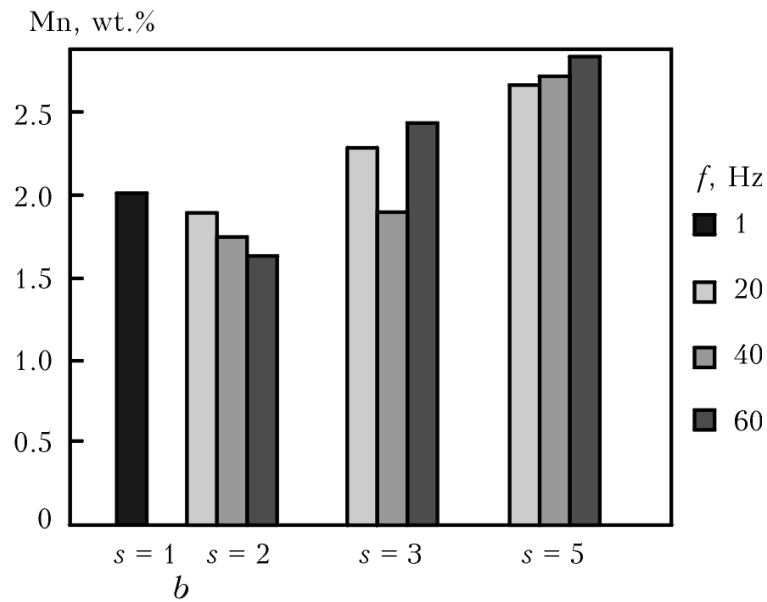

Figure 1. WF evolution in welding using wire Sv-08G2S at average current of $160 \mathrm{~A}$ and voltage of 21-22 V with constant electrode wire feed $(f=1 \mathrm{~Hz}, s=1)$ and with pulsed wire feed $(f=20,40,60 \mathrm{~Hz}, s=2,3,5): a-$ intensity of WF formation $V_{\mathrm{WF}} ; b-$ content of manganese in WF composition 


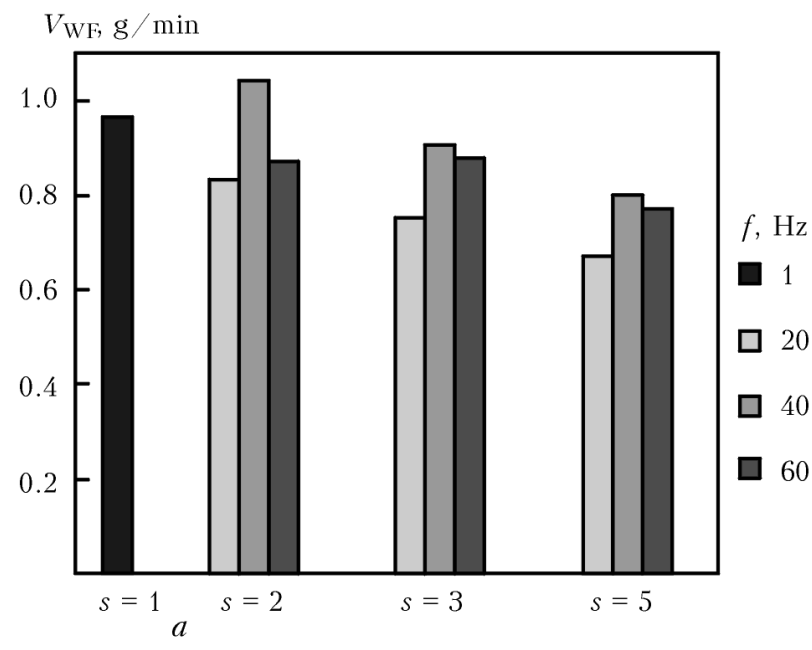

C, wt.\%

$V_{\mathrm{Cr}^{6+}}, \mathrm{g} / \mathrm{min}$
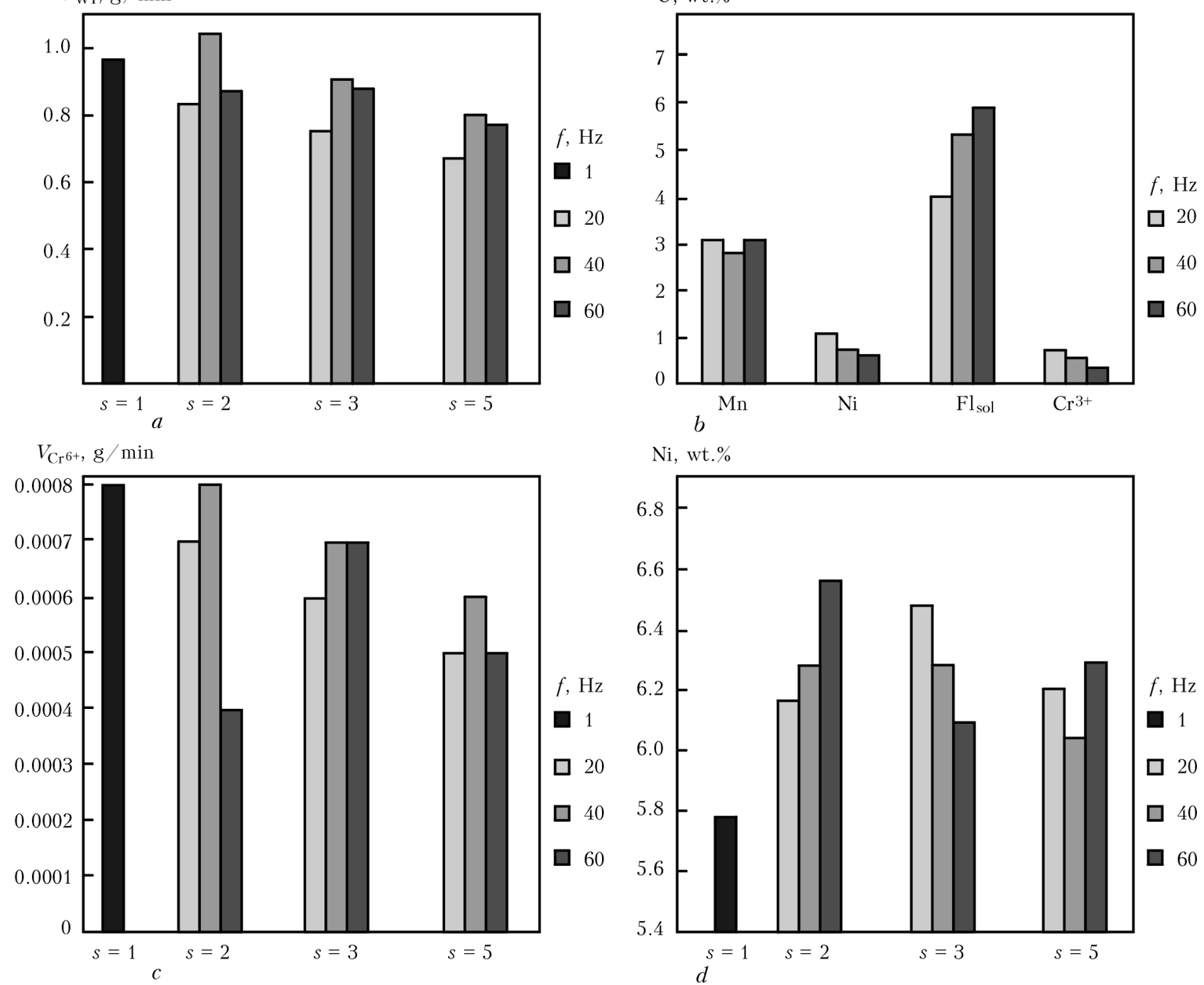

$\mathrm{Ni}, \mathrm{wt} . \%$

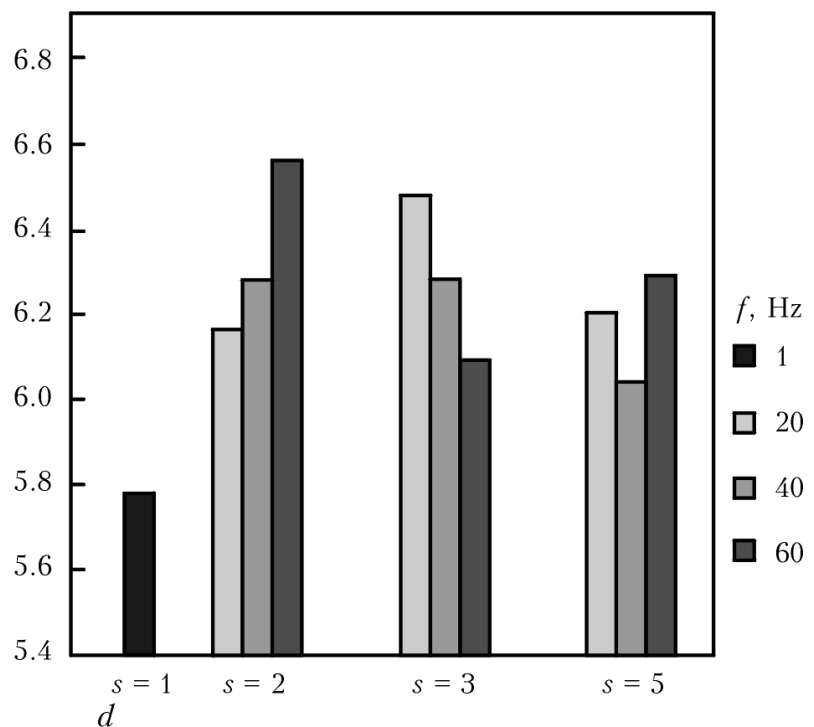

Figure 2. WF evolution in welding using wire EP-690 at $160 \mathrm{~A}$ average current and $21-22 \mathrm{~V}$ voltage with constant $(f=$ $=1 \mathrm{~Hz}, s=1)$ and with pulsed wire feed $(f=20,40,60 \mathrm{~Hz}, s=2,3,5): a$ - intensity of WF evolution; $b-$ mass fraction of $\mathrm{Mn}, \mathrm{Cr}^{3+}, \mathrm{Fl}_{\text {sol }}$ and $\mathrm{Ni}$ in the WF composition $(s=5) ; c-$ intensity of $V_{\mathrm{Cr}^{6+}}$ formation; $d-\mathrm{Ni}$ mass fraction

with pulse duration and with increase in the pause duration. Mechanized welding using pulsed current can reduce the intensity of WF evolution as compared to conventional mechanized arc welding due to decreaase in the volume of heat generated in welding zone.

Furthermore, the use of welding at pulsed current provides a significant decrease in evolution of manganese in the composition of WF [12] providing the process with a controllable forced short circuits, increasing frequency of circuits, arc length and reducing the droplet size. It is possible to reduce the manganese content in WF by adjusting the frequency of current pulses promoting the better drop detachment from the electrode and increase in frequency of their transition into the pool. The results of investigations, obtained in this work correlate well with the results of other works, on the subject of mechanized welding using modulated pulse current [2, 3, 12, 14].
The results of comparative investigations of toxic manganese content in WF, formed in welding using wire Sv-08G2S at constant and pulsed feed (Figure 1, $b$ ), show that its minimum content occurs at the pulsed electrode wire feed at $f=$ $=20,40,60 \mathrm{~Hz}$ and $s=2$ modes. The rest welding modes $f=20,40,60 \mathrm{~Hz}$ and $s=3,5$ result in somewhat increased manganese content in the composition of WF as compared to welding using continuous wire feed.

The investigation of dependencies of manganese content in the composition of WF (see Figure $1, b)$ and the intensity of its evolution on frequency and duration of pulses of electrode wire feed showed that increase in pulse duration contributes to increase in the concentration of manganese in WF and the intensity of its evolution, and the influence of pulse frequency is ambiguous. In welding with pulsed feed of electrode wire with $f=40-60 \mathrm{~Hz}$ the decrease in the value 
of pulse duration from 5 to 2 units allows reducing the content of toxic manganese in the WF composition and almost twice decreasing the intensity of its evolution.

Thus, the results of investigations of dependencies of intensity of manganese evolution, as a leading toxic component in welding using wire Sv-08G2S allow selecting the welding mode, which provides the minimum evolution of manganese to the working area air. This is the welding mode with pulsed electrode wire feed with $40-60 \mathrm{~Hz}$ frequency and pulse duration of 2 units.

Welding using wire EP-690 in $\mathrm{Ar}+\mathrm{CO}_{2}$ mixture. Applying wire EP-690 for welding with its pulsed feeding the intensity of WF formation is lower than during welding with constant wire feed, except of $f=40 \mathrm{~Hz}, s=2$ mode (Figure 2, $a)$. The use of wire EP-690 leads to release of such harmful components into the working area air as manganese, trivalent chromium, nickel (Figure 2, b), as well as hexavalent chromium. In the composition of WF the highest content has manganese, the lower belongs to trivalent chromium and nickel, and the minimum has hexavalent chromium. In this case, the most toxic component of WF is hexavalent chromium, whose results of investigated intensity of evolution are shown in Figure 2, c. From the Figure it is seen that during welding with pulsed electrode wire feed (except of $f=40 \mathrm{~Hz}, s=2$ mode) the intensity of evolution of hexavalent chromium is lower than at constant wire feed. The maximum intensity of hexavalent chromium evolution is noted in welding mode with $f=40 \mathrm{~Hz}$ and $s=2$ as compared to other welding modes with the pulsed and constant wire feed. The most acceptable mode, providing the minimum evolution of hexavalent chromium (twice lower than in welding with constant wire feed) is the mode with pulsed wire feed with $60 \mathrm{~Hz}$ frequency and pulse duration of 2 units.

Regarding nickel (the second largest toxic carcinogenic component of WF), then from the results of investigations (Figure 2, d) it is seen that its content in WF during welding using wire EP-690, on the contrary, has a minimum value at mode with constant wire feed as compared to welding with pulsed wire feed at all the investigated modes. The results of investigations of dependencies of intensity of nickel evolution at welding mode with pulsed wire feed showed that it is minimal at $f=20 \mathrm{~Hz}$ and $s=5$, and the maximum is at $f=40 \mathrm{~Hz}$ and $s=2$. It is recommended to consider this peculiarity during selection of the optimal welding mode, when the in- tensity of evolution of all the WF components in the working area is taken into account. Here it should be remembered that according to the value of the maximum permissible concentration (MPC) the toxicity of hexavalent chromium is 5 times higher than the toxicity of nickel, and many times exceeds the MPC of other components in the composition of WF.

Welding using flux-cored wire Veltek-N320 in $\mathbf{C O}_{2}$. In welding using Veltek-N320 flux-cored wiire, the composition of which besides the above-mentioned components includes also fluorines, the application of pulse mode, in most cases, allows improving the hygienic characteristics as compared to welding with constant wire feed, particularly, at modes with $20 \mathrm{~Hz}$ frequency at any pulse duration (Figure $3, a$ ).

The results of investigations of dependencies of intensity of WF formation on frequency and pulse duratione (see Figure 3,a) showed that at $s=2,3$ and 5 and $f=20 \mathrm{~Hz}$, it has a minimum value, and further at $40 \mathrm{~Hz}$ frequency it reaches the maximum and then decreases up to $60 \mathrm{~Hz}$, except of mode with $s=2$, where after the pulse frequency of $40 \mathrm{~Hz}$, the intensity of WF formation continues to grow. The determination of chemical composition of WF (Figure $3, b$ ) revealed that it contains the greatest amount of insoluble fluorines $(61.4 \%)$, followed by soluble fluorines $(18.0 \%)$, then manganese $(13.9 \%)$, nickel $(5.0 \%)$, and the lowest content of trivalent chromium (3.4\%). Remarkably that hexavalent chromium in this case is absent. The minimum content of toxic manganese in the composition of WF was observed during welding with pulsed wire feed at $f=40 \mathrm{~Hz}, s=2$, and the maximum one occured during welding with constant feed (Figure 3,c).

The investigations of intensity of dependencies of manganese evolution on frequency and pulse duration showed that they bear a complex character: at pulse frequencies of 20 and $60 \mathrm{~Hz}$ they have almost the the same values; at $f=40 \mathrm{~Hz}$ and $s=5$ the intensity of manganese evolution has the maximum value, and at $s=2$ it is the minimum. The latter confirms the previous obtained data [2] that welding with pulse current can reduce the manganese content in WF due to the control of electrode metal transfer.

The determination of soluble fluorines evolution (2nd class of hazard) shows that its maximum content was in WF formed in welding with pulsed wire feed at $f=40$ and $60 \mathrm{~Hz}$ and $s=2$, 3,5 ; the lower was in welding with constant and pulsed wire feed at $f=20 \mathrm{~Hz}$ and $s=2,3,5$ (Figure 3,d). The investigations of dependencies 

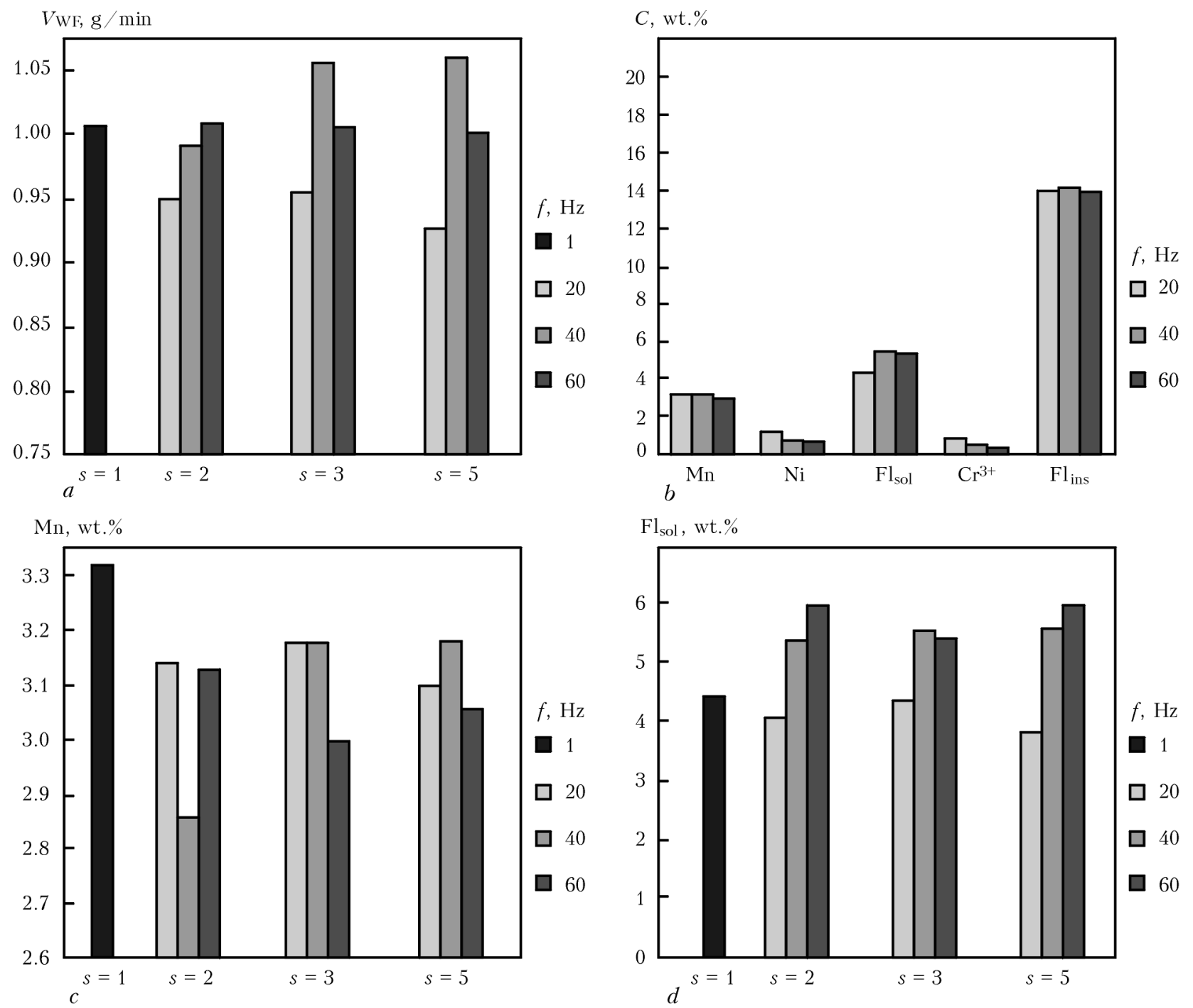

$\mathrm{Fl}_{\mathrm{sol}}$, wt.\%
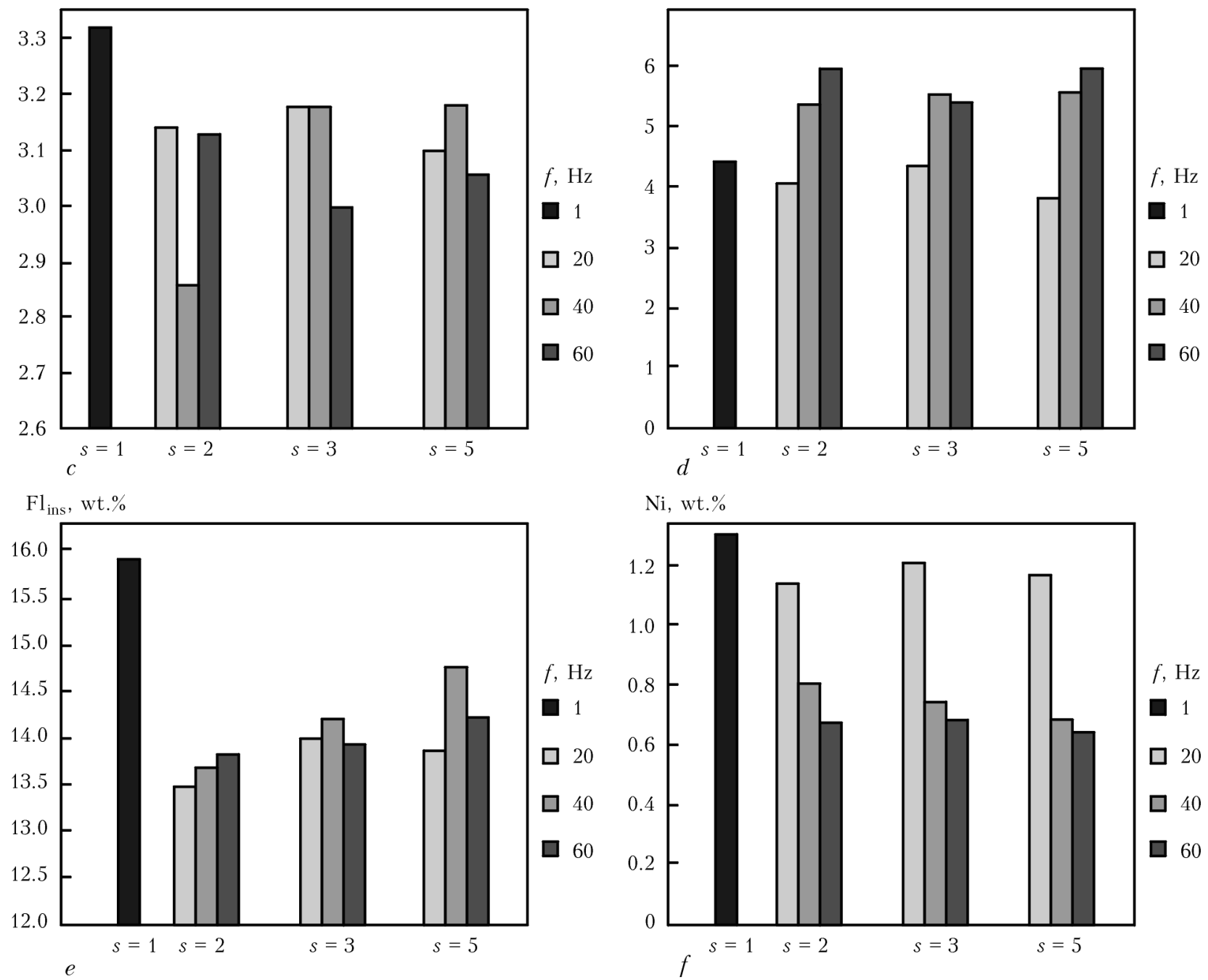

Figure 3. WF evolution in welding using wire Veltek-N320 at 230 A average current and 26-27 V voltage with constant $(f=1 \mathrm{~Hz}, s=1)$ and with pulsed wire feed $(f=20,40,60 \mathrm{~Hz}, s=2,3,5): a-$ intensity of WF formation; $b-$ mass fraction of harmful substances in WF $(s=3) ; c-$ Mn mass fraction; $d-$ mass fraction of soluble fluorine; $e-$ mass fraction of insoluble fluorine; $f-\mathrm{Ni}$ mass fraction in WF

of intensity of soluble fluorine formation on the frequency and duration of pulse showed that in welding with $s=3$ and 5 at $f=20-40 \mathrm{~Hz}$ it is increased, and from 40 to $60 \mathrm{~Hz}$ it is reduced, except of pulse duratioon of 2 units, where the intensity of soluble fluorine formation constantly grows. The insoluble fluorine (3rd class of hazard) is present in WF in the maximum volume 
in case of welding at constant electrode wire feed and in much smaller volumes in welding with pulsed wire feed at all the modes (Figure 3,e).

The investigation of nickel content (1st class of hazard) in WF (Figure 3,f), as the leading toxic component in this case, showed that its minimum volume was observed in welding with pulsed flux-cored wire feed at $f=40$ and $60 \mathrm{~Hz}$ and $s=2,3$ and 5, and the maximum was in welding with constant pulsed wire feed and also on modes with pulsed wire feed at $20 \mathrm{~Hz}$ and 2 , 3,5 units. The dependencies of intensity of nickel evolution on pulse frequency are reduced with its increase. Therefore, in this case (in the absence of hexavalent chromium in WF) during selection of welding modes providing the minimal influence of WF on the body of welder, it is necessary to focus on nickel.

Thus, from the obtained data it was revealed that the intensity of WF formation, volume of evolved impurities and their mass fraction in the WF composition are rather sensitive to changes in voltage in the range of $\pm(1.5-2) \mathrm{V}$, which occurs at the pulse electrode wire feed. It depends on the type of electrode metal transfer, type of electrode wire and level of its alloying. The application of pulsed electrode wire feed provides not only the control of the size of molten droplet through a feed step, but also presets the type of electrode metal transfer. Thus, when using fluxcored wire Veltek-N320 at $f=40$ and $60 \mathrm{~Hz}$ and $s=2,3$ and 5 the spray transfer with a frequent modulation of arc length was observed and, consequently, its voltage, that eventually resulted in reduction of nickel vapors content (the lowest evolution of nickel is provided at modes with pulsed wire feed at $f=40$ and $60 \mathrm{~Hz}$ ). The transition to globular metal transfer with short circuits at $f=20 \mathrm{~Hz}$ did not change significantly the level of nickel content as compared to the constant electrode wire feed, but influenced the rate of WF formation and content of vapors of other compounds in it. Whereas in case with solid electrode wire EP-690 its capability of pulsed feeding influences the type of electrode metal transfer and allows obtaining the stable process with short circuits at $s=5$ and $f=20 \mathrm{~Hz}$, that, as a result, has a positive effect on the intensity of WF formation, and almost twice reduction of intensity of hexavalent chromium evolution. The same regularities, associated with the influence of pulsed electrode wire feed parameters on the volume of drop, duration of its staying at the end of electrode wire, duration of drop transfer to the weld pool, are observed in case of welding with electrode wire Sv-08G2S. In welding with pulsed feed using this wire in the mixture of shielding gases $\mathrm{Ar}+\mathrm{CO}_{2}$, the intensity of $\mathrm{WF}$ evolution decreases from 1.2 to 2 times as compared to welding using continuous wire feed.

From all the mentioned above, it follows that welding with a controllable pulsed electrode wire feed improves hygienic characteristics of this process as compared to welding using continuous feed and to some extent provides their control at accurate presetting of pulsed electrode wire feed parameters and the whole complex of welding equipment. It is recommended to use the obtained results of investigations when selecting the welding modes with a controllable pulsed electrode wire feed.

1. Golovatyuk, A.P., Sidoruk, V.S., Levchenko, O.G. et al. (1985) Intensity of aerosol formation in manual modulated-current welding. Avtomatich. Svarka, 2, 39-40.

2. Levchenko, O.G. (2000) Formation of aerosols in $\mathrm{CO}_{2}$ modulated-current welding. The Paton Welding J., 8, 47-49.

3. Castner, H.R. (1995) Gas metal arc welding using pulsed fume generation current. Welding Res. Suppl., February, 59-68.

4. Lebedev, V.A. (2014) Specifics of control of consumable electrode welding process with pulsed electrode wire feed. Svarka i Diagnostika, 1, 16-18.

5. Palmer, W.G., Eaton, J.C. (2007) Effects of welding on health: AWS Int. Standard Book 978-0-87171067-3.

6. Antonini, J.M. (2003) Health effects of welding. Critical Rev. in Toxicology, 33(1), 61-103.

7. ANSI Z49.1-2005: Safety in welding, cutting and allied processes, Sect. E5.4, 12. AWS.

8. Lebedev, V.A., Lendel, I.V. (2013) Control of pulsed movement of electrode wire in mechanized welding due to change of feed pitch. Zagotovitel. Proizv. v Mashinostroenii, 3, 10-14.

9. Potapievsky, A.G., Saraev, Yu.N., Chinakhov, D.A. (2012) Consumable-electrode shielded-gas welding of steels. Technique and technology of future. Tomsk: TPU.

10. DSTU ISO 15011-1:2008: Occupational health and safety in welding and allied processes. Laboratory method of aerosol and gas extraction formed in arc welding. Pt 1: Determination of emission level and sampling for analysis of aerosol microparticles. Valid from 2008-8-15. Kyiv: Derzhstandart Ukrainy.

11. (1990) 4945-88: Guidelines for determination of harmful substances in welding aerosol (solid phase and gases). Moscow: Minzdrav SSSR.

12. Levchenko, O.G. (1986) Influence of shielded gas composition and welding parameters on bulk emissions of welding aerosol. Avtomatich. Svarka, 1, 73-74.

13. Voropaj, N.M., Benidze, Z.D., Buchinsky, V.N. (1989) Peculiarities of $\mathrm{CO}_{2}$ welding process with pulsed electrode wire feed. Ibid., 2, 23-26, 36.

14. Levchenko, O.G. (1992) Influence of technological parameters of $\mathrm{CO}_{2}$ welding of structural steels on aerosol emission. Ibid., 9/10, 31-33. 